\title{
Incidence and Cause of Delirium in Hospitalized Patients between the Ages of 18 and 56: A Retrospective Chart Review
}

\author{
Michelle T. Weckmann, ${ }^{1,2}$ Camden Bay, ${ }^{1}$ Nesrin Abu Ata, ${ }^{1}$ and R. Sean Morrison ${ }^{3,4}$ \\ ${ }^{1}$ Department of Family Medicine, University of Iowa Carver College of Medicine, Iowa City, IA 52242-1000, USA \\ ${ }^{2}$ Department of Psychiatry, University of Iowa Carver College of Medicine, Iowa City, IA 52242-1000, USA \\ ${ }^{3}$ Brookdale Department of Geriatrics and Palliative Medicine, Mount Sinai School of Medicine, New York, NY 10029-6574, USA \\ ${ }^{4}$ Geriatric Research, Education and Clinical Center, James J. Peters VA Medical Center, Bronx, NY 10468, USA
}

Correspondence should be addressed to Michelle T. Weckmann; michelle-weckmann@uiowa.edu

Received 20 June 2013; Accepted 11 November 2013; Published 28 January 2014

Academic Editors: S. Bhatnagar, S. Komurcu, and S. Noble

Copyright (C) 2014 Michelle T. Weckmann et al. This is an open access article distributed under the Creative Commons Attribution License, which permits unrestricted use, distribution, and reproduction in any medium, provided the original work is properly cited.

Background. Delirium is a common and devastating condition which has been well characterized in elderly cancer patients, but little is known about delirium in cancer patients under the age of 65. Aim. A pilot study to explore the incidence and potential causes of delirium in hospitalized advanced cancer patients at the age of 18-56 years. Design. A retrospective chart review using validated instruments was used to examine the charts of hematology-oncology admissions in a large academic institution. Data was collected as to the likelihood of delirium and potential precipitants. Results. Delirium incidence was $29 \%$ among advanced cancer patients. The associated precipitants of delirium were multifactorial, the most common being medications and infection. Delirium was more common in patients admitted for either acute symptom management or the presence of a lung malignancy. Patients with delirium demonstrated significantly increased total hospital cost and a borderline significant result for increased mortality compared to those without delirium. Conclusions. Delirium is common in hospitalized advanced cancer patients (age 18-56 years) and the cause is typically multifactorial. Delirium results in a more complicated hospital course and likely increased mortality. Further research is needed to define strategies to prevent and treat this common and distressing condition.

\section{Introduction}

Delirium is a rapidly developing disturbance in consciousness that includes confusion, disorientation, hallucinations, and agitation. Symptoms fluctuate during the day and are caused by a medical condition. Delirium is common (18-44\%) in hospitalized patients with cancer and has a significant negative impact on patients, families, and caregivers [1-3]. Delirium has been correlated with a host of negative outcomes including the following: patient distress and increased rates of mortality, cognitive impairment, dementia, depression, posttraumatic stress disorder, and poor quality of life [1, 4-13]. Although the negative impact of delirium is well established, it remains underrecognized and undertreated. In advanced cancer patients, staff missed the diagnosis of delirium $44 \%$ of the time and younger patients were more likely to be misdiagnosed $[14,15]$. The majority of delirium research has not included younger patients with advanced cancer, leading to a focused gap in our knowledge. With few exceptions, studies of delirium have been in older patients demonstrating a prevalence of $28-48 \%$; however, early data indicate that delirium may be common in cancer patients under the age of 56 , with an incidence over $50 \%$ in some cancer populations $[16,17]$.

Once delirium develops, initial management involves treating the underlying medical cause. Studies have shown that the cause of delirium is typically multifactorial $[2,18,19]$. Both risk factors and precipitating causes of delirium have been identified in older patients with cancer. Risk factors include advanced age and cognitive impairment, while associated precipitants include hematological malignancies, medications, hypoxia, dehydration, and inflammation. Studies of 


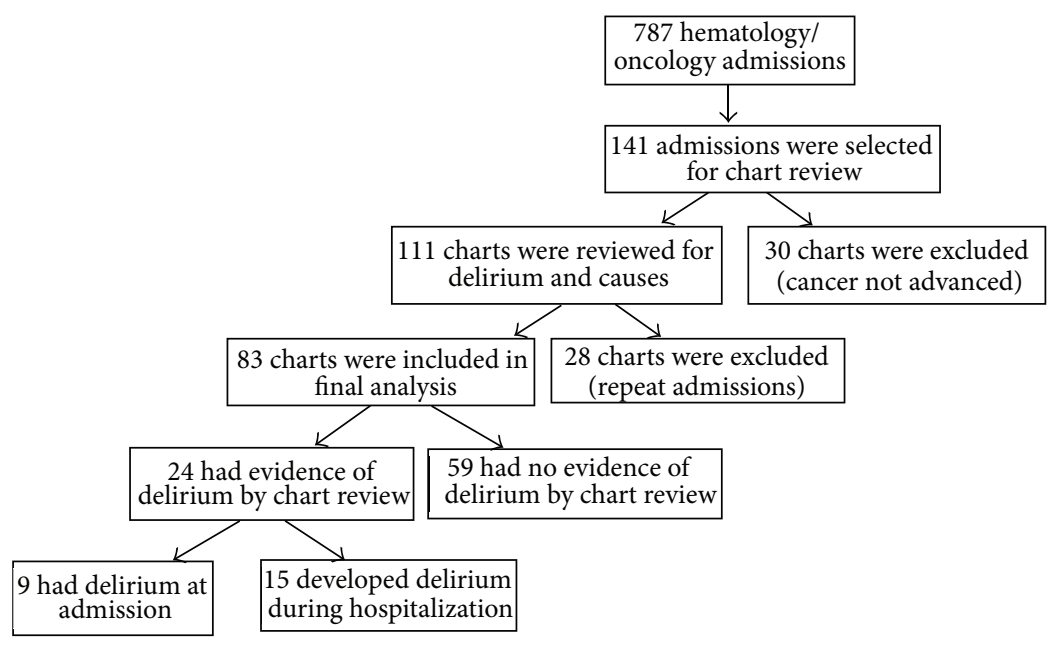

FIGURE 1

causes, however, report inconsistent results which may be related to variations in the populations being studied or the causes of delirium may be disease specific [2, 18, 20-23]. This pilot study was designed to use previously validated chart review methods to explore the incidence and associated precipitants of delirium in hospitalized patients with advanced cancer, age 18-56 years [23, 24]. Subanalysis was performed to explore delirium impact on mortality, hospital cost, and length of stay. The data from this pilot study provides information on the rate of delirium in hospitalized patients with advanced cancer, aged $18-56$ years, and will be used to support the need for further funding to study the actual incidence of delirium and to design a delirium prediction model for this population.

\section{Materials and Methods}

2.1. Patients. Institutional review board (IRB) approval was obtained to examine the charts of hematology-oncology admissions (age 18 to 56 years) at a large academic hospital in 2009. Dementia is increasingly common in patients older than 65 years. 56 years was used as the upper age in order to limit the confounding factors of a preexisting cognitive impairment or dementia. There were 787 hematologyoncology admissions in 2009 and, of those, the first 12 admissions for each month were selected for the chart review. If multiple admissions from the same patient appeared in the sample, one admission was randomly chosen and the others were excluded to preserve independence among observations. Thirty charts were excluded because the patient did not have advanced cancer $(n=26)$ or cancer had not been confirmed $(n=4)$. Advanced cancer was designated as cancer which has spread beyond its site of origin or any cancer with a poor 5-year survival (e.g., pancreatic cancer) [25]. A detailed chart review for delirium was completed for 111 admissions with 28 repeat admissions eliminated (Figure 1). The reasons for admission were divided into four categories: surgical resection, chemotherapy, acute symptom management, or hematopoietic stem cell transplantation.

2.2. Chart Review. Chart reviews were conducted by physicians dually trained in both family medicine and psychiatry with extensive delirium experience. The charts selected for full review were examined using Inouye's validated method to determine delirium by chart review [24]. This method involves a detailed review of all aspects of the chart looking for surrogate descriptors for delirium, such as confusion or mental status changes. Inouye's chart review instrument was $74 \%$ sensitive and $83 \%$ specific in elderly hospitalized patients when compared with the confusion assessment method for diagnosing delirium. Inouye's original study showed that the most common factors associated with incorrect delirium identification were dementia, severe illness, and a high baseline delirium risk. Inouye concluded that the chart review instrument was not appropriate for individual patient care; however, it is an effective, easy way to expand delirium identification. All entries into the electronic medical record were reviewed in detail to determine if key terms for identification of delirium were present. The presence and then absence of key terms for delirium were used to determine the length of the delirium episode.

We used Brauer's instrument for determining the cause of delirium in elderly patients following a hip fracture which classifies possible causes of delirium into 8 categories (drug induced, infection, fluid-electrolyte disturbance, metabolic and endocrine disturbances, cardiopulmonary compromise and/or hypoxia, alcohol and drug withdrawal, and sensory/environmental) [23]. The causes are then classified as definite, probable, possible, or comorbid based on the number of criteria present for each case.

Patient survival was determined by electronic medical record review and query of both the Cancer Center database and the social security website for date of death. Available cost data was obtained from hospital administration and consisted of in-total hospital costs, which includes all actual 
costs for the hospitalization (physician charges, medication, room charges, tests and procedures, etc.).

2.3. Statistics. Statistical analysis was conducted using SAS 9.2 for Windows (SAS Institute, Inc., Cary, NC) and the Kaplan-Meier plot was constructed using R, version 2.13.0 (R Project for Statistical Computing, http://www.r-project .org/). Unless otherwise noted, all analyses were performed with the final sample of 83 advanced cancer patients described in the Patients section. Standard descriptive statistics (age, sex, and race) were tested with a Wilcoxon rank-sum, independent samples $t$-test, Pearson chi-square, or Fisher's exact test to compare those with and without delirium. Fisher's exact test was used for sparse data with race while the Wilcoxon rank-sum test was used for nonnormal age data. The age distributions for those with and without delirium had dissimilar shapes, which allowed for a rejection of the ranksum null hypothesis due to factors other than different medians. A $t$-test was used on the log of age to verify results from the rank-sum test. Every patient had a single type of cancer and a single reason for admission associated with hospital admission. A Fisher's exact test was used to compare delirium status with cancer incidence and admission reason. Linear regression models were utilized to measure the association between delirium status and the length of hospital stay and total hospital cost. Regression analysis was chosen because it allowed for the control of confounders; for these models, age and sex were considered potentially confounding variables. Regression diagnostics revealed that both models severely violated the assumptions of homoscedasticity and normality of the residuals. To remedy this, the log of length of stay and the log of total cost were used as responses in their respective models. Three patients had outlying lengths of stay $(35,38$, and 52 days), so results were reported with and without their influence. Four patients had outlying total costs greater than $\$ 100,000$, so results were reported with and without them in the sample. Detecting outliers is a subjective activity, so it deserves explanation. For this study, observations were considered outliers if their location was distant from other observations and did not appear to be following the same pattern defining the rest of the data, as based on a histogram or box plot. They were determined not to be erroneous values; instead they were abnormal occurrences that had substantial influence on estimates gleaned from the regression analyses.

Many patients died within 12 months of admission, so it was of interest to explore the association between delirium status and mortality. By creating an exact logistic regression model with death status within 12 months of admission as the response, this association was measured (controlling for age and sex). An exact logistic regression model was constructed to analyze the association between advanced cancer status (advanced cancer or no advanced cancer) and death status within 12 months of admission. This model also included 26 of the 30 charts with no indication of advanced cancer; the 4 charts without definitive evidence of cancer were excluded. A Kaplan-Meier plot was constructed for patients with and without delirium (Figure 2). Patients would be considered censored if they were still alive on the first of January, 2011, and all-cause mortality was considered the event. Patients

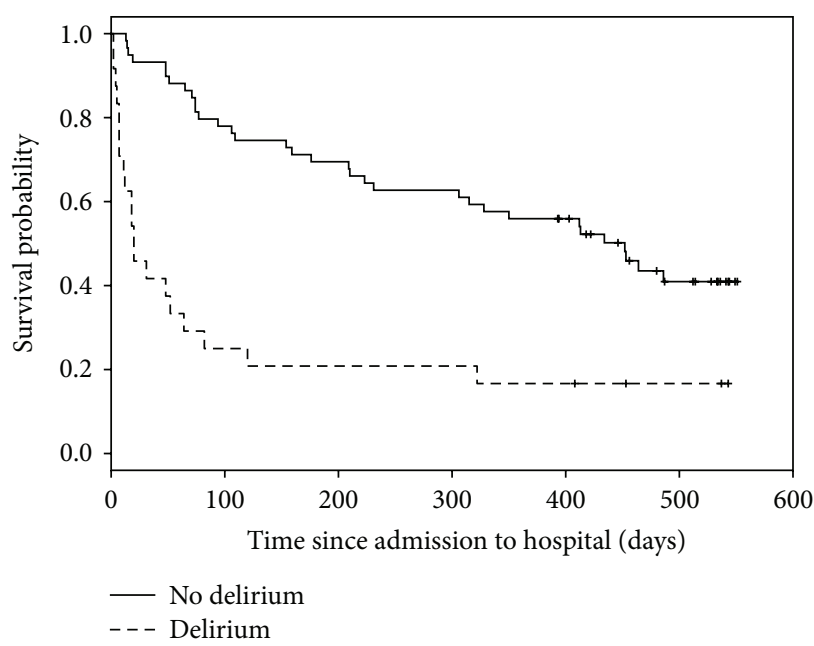

FIgURE 2: Kaplan-Meier delirium survival curve.

were entered into the survival analysis beginning with their admission to the hospital. $P$ values less than 0.05 were considered significant and all tests were two-tailed.

\section{Results}

Nine of the patients were delirious at the time of admission. Additional 15 patients developed delirium during admission. Overall, 24/83 (29\%) of the charts showed evidence of delirium during hospitalization (Figure 1). The mean length of delirium was 5.04 days (median 2 days, range 1 to 32). Of the 20 patients with delirium who were alive at discharge, 6 patients (30\%) still showed evidence of delirium on the day of discharge.

Overall sample characteristics can be seen in Table 1. Sex and race did not show significant evidence of being related with delirium, but age did. The mean age of those with delirium is 51.42 (median 51.50) and those without 43.03 (47.0), with the Wilcoxon rank-sum test resulting in $P<$ 0.01 . The rank-sum results for age were verified with a $t$-test performed on the log of age $(P<0.0001)$. Delirium was associated with cancer type and reason for admission $(P<$ 0.01 and $<0.0001$, resp.). The incidence of each type of cancer by delirium and each admission reason is recorded in Table 1. Delirium frequency was higher for those with lung cancer ( $86 \%, 95 \%$ CI $42 \%$ to $99 \%$ ), in patients who had a nonelective admission for acute symptom management (58\%, 95\% CI $39 \%$ to $75 \%$ ), and in patients admitted for hematological stem cell transplantation ( $44 \%, 95 \%$ CI $14 \%$ to $79 \%)$. No patients were admitted for surgical resection, and only $3 \%$ $(1 / 32)$ of patients were admitted for chemotherapy, developed delirium. The consensus causes of delirium are shown in Table 2. The 24 patients with delirium were evaluated for eight different potential causes (each cause had 3 criteria). Patients were classified with associated precipitants a total of 70 times. A definite cause was found 2 times, probable causes were found 40 times, and possible causes were found 2 times. Five identifiable causes were found to be comorbid 26 times. 
TABLE 1: Categorical sample descriptors.

\begin{tabular}{|c|c|c|}
\hline & Frequency of subjects with no delirium & Frequency of subjects with delirium \\
\hline \multicolumn{3}{|l|}{ Gender } \\
\hline Male & $35(0.73)$ & $13(0.27,0.15$ to 0.42$)$ \\
\hline Female & $24(0.69)$ & $11(0.31,0.17$ to 0.49$)$ \\
\hline \multicolumn{3}{|l|}{ Race } \\
\hline White & $51(0.73)$ & $19(0.27,0.17$ to 0.39$)$ \\
\hline Asian & $1(1.0)$ & $0(0.0,0.0$ to 0.98$)$ \\
\hline Hispanic & $2(0.67)$ & $1(0.33,0.0$ to 0.91$)$ \\
\hline Black & $2(0.67)$ & $1(0.33,0.0$ to 0.91$)$ \\
\hline Native American & $1(1.0)$ & $0(0.0,0.0$ to 0.98$)$ \\
\hline Other & $2(0.40)$ & $3(0.60,0.15$ to 0.95$)$ \\
\hline \multicolumn{3}{|l|}{ Cancer type } \\
\hline Lung & $1(0.14)$ & $6(0.86,0.42$ to 0.99$)$ \\
\hline Central nervous system & $3(0.50)$ & $3(0.50,0.12$ to 0.88$)$ \\
\hline Gastrointestinal & $5(0.63)$ & $3(0.38,0.09$ to 0.76$)$ \\
\hline Hematological & $23(0.72)$ & $9(0.28,0.14$ to 0.47$)$ \\
\hline Sarcoma & $5(0.83)$ & $1(0.17,0.0$ to 0.64$)$ \\
\hline Head and neck & $7(0.88)$ & $1(0.13,0.0$ to 0.53$)$ \\
\hline Breast & $1(1.0)$ & $0(0.0,0.0$ to 0.98$)$ \\
\hline Genitourinary & $0(0.0)$ & $1(1.0,0.03$ to 1.0$)$ \\
\hline Gynecological & $11(1.0)$ & $0(0.0,0.0$ to 0.28$)$ \\
\hline Neuroendocrine & $2(1.0)$ & $0(0.0,0.0$ to 0.84$)$ \\
\hline Skin & $1(1.0)$ & $0(0.0,0.0$ to 0.98$)$ \\
\hline \multicolumn{3}{|l|}{ Reason for admission } \\
\hline Surgical resection & $9(1.0)$ & $0(0.0,0.0$ to 0.34$)$ \\
\hline Chemotherapy & $31(0.97)$ & $1(0.03,0.0$ to 0.16$)$ \\
\hline Hematological stem cell transplantation & $5(0.56)$ & $4(0.44,0.14$ to 0.79$)$ \\
\hline \multirow[t]{2}{*}{ Acute symptom management } & $14(0.42)$ & $19(0.58,0.39$ to 0.75$)$ \\
\hline & No delirium $(n=59)$ & Delirium $(n=24)$ \\
\hline \multicolumn{3}{|l|}{ Age } \\
\hline Mean & 43.03 & 51.42 \\
\hline Median & 47.0 & 51.50 \\
\hline Standard deviation & 11.66 & 3.72 \\
\hline \multicolumn{3}{|l|}{ Length of stay (days) } \\
\hline Mean & 5.56 & 11.21 \\
\hline Median & 4.0 & 6.50 \\
\hline Standard deviation & 5.64 & 13.24 \\
\hline \multicolumn{3}{|l|}{ Total cost } \\
\hline Mean & 15846.03 & 43686.29 \\
\hline Median & 9488.0 & 20654.50 \\
\hline Standard deviation & 18970.49 & 63617.43 \\
\hline
\end{tabular}

Parentheses contain proportion; exact 95\% confidence interval follows the proportion in the subjects with delirium column.

The most frequent causes were medications and infection. There were no causes assigned to sensory/environmental (defined as pre-existing dementia or severe visual or hearing impairment) or drug withdrawal.

While controlling for the confounding effect of age, having delirium was found to increase length of stay by $48.64 \%$ (95\% confidence interval $-8.45 \%$ to $141.34 \%$ ) but was nonsignificant with $P=0.11$. (Table 3 ). Removing the three outliers provided a nonsignificant $(P=0.57)$ estimate of
$14.19 \%$ (95\% CI $-28.50 \%$ to $82.37 \%$ ). These nonsignificant results for the effect of delirium on length of stay were verified by using a Wilcoxon rank-sum test stratified by a categorical representation of age. Neither age nor sex was determined to be a confounder between delirium and total cost, so estimates were made with a simple model. The presence of delirium significantly increased total cost by $105.70 \%$ (95\% CI $27.99 \%$ to $230.60 \%$ ) with $P<0.01$. Removal of the outliers led to an estimate of $58.86 \%$ with $P=0.04$ and a $95 \%$ CI of 
TABLE 2: Consensus causes of delirium among 24 hospitalized patients (age 18-55 years) with advanced cancer.

\begin{tabular}{lccccc}
\hline & Definite $^{1}$ & Probable $^{2}$ & Possible $^{3}$ & Comorbid $^{4}$ & Total $^{2}$ \\
\hline Drugs & 2 & 7 & 0 & 11 & 7 \\
Infection & 0 & 5 & 1 & 3 & 13 \\
Fluid-electrolyte & 0 & 6 & 0 & 2 & 9 \\
Metabolic/endocrine & 0 & 3 & 0 & 0 & 3 \\
Intracranial & 0 & 11 & 1 & 0 & 11 \\
Cardiopulmonary & 0 & 0 & 0 & 0 \\
Drug withdrawal & 0 & 0 & 0 & 0 \\
Sensory/environmental & 0 & 8 & 0 & 0 \\
\hline
\end{tabular}

${ }^{1}$ Definite met all 3 criteria for only one potential cause of delirium. ${ }^{2}$ Probable met all 3 criteria for a potential cause of delirium but criteria for other causes were also present. ${ }^{3}$ Possible met 2 criteria for a potential cause of delirium and no criteria for any other causes. ${ }^{4}$ Comorbid met only 1 or 2 criteria for a potential cause of delirium.

TABLE 3: Linear regression models for log length of stay and log total cost.

\begin{tabular}{lllcc}
\hline Response & Predictor & Coefficient $(95 \%$ CI $)$ & Standard error & $P$ value \\
\hline $\begin{array}{l}\text { Model 1: } \log \text { length of stay, } \\
\text { including outliers }(n=83)\end{array}$ & Delirium & $0.40(-0.09$ to 0.88$)$ & 0.24 & 0.11 \\
\hline $\begin{array}{l}\text { Model 2: } \log \text { length of stay, } \\
\text { excluding outliers }(n=80)\end{array}$ & Age & $\begin{array}{c}0.01(-0.01 \text { to } 0.03) \\
\text { Aelirium }\end{array}$ & $0.13(-0.34$ to 0.60$)$ & 0.01 \\
\hline $\begin{array}{l}\text { Model 3: } \log \text { total cost, } \\
\text { including outliers }(n=83)\end{array}$ & Age & $0.01(-0.01$ to 0.03$)$ & 0.24 & 0.01 \\
\hline $\begin{array}{l}\text { Model 4: } \log \text { total cost, } \\
\text { excluding outliers }(n=79)\end{array}$ & Delirium & $0.72(0.25$ to 1.19$)$ & 0.24 & 0.34 \\
\hline
\end{tabular}

CI: Confidence interval.

$2.46 \%$ to $146.31 \%$. These significant results were then verified with a Wilcoxon rank-sum test. With age included as a confounder, the odds ratio for having delirium and dying within 12 months of admission was found to be 3.67 (95\% CI .96 to 17.58) but was not significant with $P=0.06$ (Table 4 ). The confounding effect of age on the relationship between having delirium and dying within 12 months of admission was substantial. Without controlling for this effect, the odds ratio was 6.21 (95\% CI 1.78 to 28.09 ) with $P<0.01$. With age included as a confounder, the odds ratio for having advanced cancer and dying within 12 months of admission was 15.79 (95\% CI 3.36 to 151.93 ), with $P<0.0001$. Only 2 of the 26 patients $(8 \%)$ who did not have advanced cancer died in the 12 months following admission, while 46 of the 83 patients (55\%) with advanced cancer died in the 12 months following admission. Of the 83 patients with advanced cancer, a larger proportion of the patients died in the group with delirium $(20 / 24)$ versus those in the group without delirium (26/59) within 12 months of admission. Figure 2 uses a Kaplan-Meier plot to illustrate how delirium affects survival probability.

\section{Discussion}

The results of this pilot study suggest that delirium is common in hospitalized patients with advanced cancer, age 18-56 years, and that the causes for delirium are multifactorial. The majority of studies examining delirium in cancer patients looked at older patients or patients who were admitted for a terminal admission. This study suggests that advanced cancer patients under the age of 56 should also be considered to have a high risk for developing delirium. Ljubisavljevic and Kelly, examined 113 patients (mean age 53) admitted to a general oncology ward and found a delirium incidence of $18 \%$; however, this sample was not specific to patients with advanced cancer [2]. Our incidence is very close to Neufeld's 2010 study which demonstrated a delirium incidence of $26 \%$ on a general oncology ward based on a prospective, goldstandard, psychiatric interview [26]. It is worth noting that Neufeld included all adult oncology patients admitted to a general oncology ward (age range 46-70) and did not define whether disease stage was related to the development of delirium.

Our finding that delirium was very common in patients with lung cancer (6/7 patients had delirium) may be demonstrating a previously unexplored risk that may be related to the age of the patient or a cardiopulmonary cause (such as hypoxia) which is common in these patients. While the finding is provocative, given the small sample size, it is preliminary and larger studies are needed to show if lung cancer places a patient under the age of 56 at higher risk for developing delirium.

We identified a definite cause of delirium in only 2 patients. The majority of cases were classified as possible or comorbid, indicating that several factors likely contributed to developing delirium. These results are similar to Brauer who found that the majority of delirium causes were multifactorial and hypothesized that differences in causes exist in different populations [23]. Our population of younger cancer patients 
TABLE 4: Exact logistic regression models for dying within 12 months of admission.

\begin{tabular}{|c|c|c|c|c|c|}
\hline Response & Predictor & Coefficient $(95 \% \mathrm{CI})$ & $\begin{array}{l}\text { Standard } \\
\text { error }\end{array}$ & Odds ratio ( $95 \% \mathrm{CI})$ & $P$ value \\
\hline \multirow{2}{*}{$\begin{array}{l}\text { Model 5: death within } 12 \text { months of } \\
\text { admission }(n=83)\end{array}$} & Delirium & $1.30(-0.04$ to 2.87$)$ & 0.63 & 3.67 (0.96 to 17.58$)$ & 0.06 \\
\hline & Age & 0.07 (0.02 to 0.13$)$ & 0.03 & $1.08(1.02$ to 1.14$)$ & $<0.01$ \\
\hline \multirow{2}{*}{$\begin{array}{l}\text { Model 6: death within } 12 \text { months of } \\
\text { admission }(n=109)\end{array}$} & $\begin{array}{l}\text { Advanced } \\
\text { cancer }\end{array}$ & $2.76(1.21$ to 5.02$)$ & 0.78 & 15.79 (3.36 to 151.93$)$ & $<0.0001$ \\
\hline & Age & $0.08(0.04$ to 0.13$)$ & 0.02 & $1.09(1.04$ to 1.14$)$ & $<0.001$ \\
\hline
\end{tabular}

CI: Confidence interval.

showed different risk factors than Brauer's population, which consisted of elderly patients following a hip fracture. Not surprisingly, the biggest difference was the lack of impact from sensory/environmental factors. Brauer was also able to place a more definitive classification on the cause of delirium in his population of elderly patients. It is possible that if we had prospectively looked for both delirium and risk factors/causes, our findings may have resulted in more definitive causes of delirium. Nevertheless, we believe this is unlikely and believe that the observed variance in assignment of cause was mainly the result of differences in patient populations. It more likely reflects the underlying medical severity of these patients which is supported by the fact that the majority of patients who developed delirium were acutely ill and were admitted for symptom management not chemotherapy.

This study suggests that patients with delirium require more expensive care, but substantial evidence was not found to show that they remain in the hospital longer. Ljubisavljevic showed that delirium doubled the length of stay from 4.5 to 8.8 days in 156 general oncology admissions despite an average delirium duration of 2.1 days [2]. This pilot study showed a longer average duration of delirium (5 days) which may be related to our patient population only including patients with advanced cancer. The increased mean length of stay is better correlated with the average length of the delirium in this study, but the wide variation makes drawing a definitive conclusion difficult and further studies are needed.

This study was designed to be exploratory in nature and, while the results are not unexpected, the findings are less than certain given the manner of data collection and the use of a chart diagnosis to identify delirium. Both the retrospective nature of the study and the use of charting to identify delirium introduce unavoidable bias and the true incidence of delirium may be either higher or lower. In general, a retrospective design tends to diminish the sensitivity of detection. Additionally, we suspect that the true incidence of delirium is higher given the fact that we relied on the medical records to determine if a patient showed evidence of delirium, which necessitates that the signs of delirium are both noticed and documented. Studies have shown that symptoms of delirium are often not noticed [27], especially if the patient is not agitated. In addition, Inouye found more false negatives in patients with severe illness (false positives were more common in patients with dementia) and our population included patients with severe illness but not dementia. Alternatively, it is also possible that the true incidence of delirium is lower and we were overvigilant in reviewing the medical records. This instrument may be more sensitive at identifying patients who may have experienced subsyndromal delirium but would not have met full criteria for delirium upon formalized testing. The retrospective nature of the chart review also calls into question the determination of delirium in patients with central nervous system involvement. The chart review instrument depends on documentation of confusion, which may be more common in patients with CNS damage and indicative of the CNS damage and not an underlying delirium. In addition, there was a trend towards delirium in older patients (Table 1) which was not significant. Another limitation of this study was the small sample size. The sample size contributed to having broad confidence intervals and, as a result, hindered the accuracy of statistics and their usefulness as a representation of the population parameters they aimed to estimate. A larger prospective study would provide clarity.

\section{Conclusions}

This study provides evidence that delirium is common in patients, age 18-56 years, with advanced cancer and delirium causes may be population/disease specific. It also suggests that delirium increases the cost of hospitalization. Little delirium research has been carried out in this patient population. In order to design an effective treatment and prevention strategy it will be important to understand which cancer patients are affected by delirium. Data from this pilot study is being used to design further studies to prospectively identify delirium and risk factors in hospitalized patients with advanced cancer, age $18-56$ years. It is hoped that those studies will provide data to design targeted prevention studies.

\section{Conflict of Interests}

The authors declare that there is no conflict of interests regarding the publication of this paper.

\section{References}

[1] P. G. Lawlor, B. Gagnon, I. L. Mancini et al., "Occurrence, causes, and outcome of delirium in patients with advanced cancer: a prospective study," Archives of Internal Medicine, vol. 160, no. 6, pp. 786-794, 2000. 
[2] V. Ljubisavljevic and B. Kelly, "Risk factors for development of delirium among oncology patients," General Hospital Psychiatry, vol. 25, no. 5, pp. 345-352, 2003.

[3] M. Z. Cohen, E. A. Pace, G. Kaur, and E. Bruera, "Delirium in advanced cancer leading to distress in patients and family caregivers," Journal of Palliative Care, vol. 25, no. 3, pp. 164-171, 2009.

[4] C. Centeno, Á. Sanz, and E. Bruera, "Delirium in advanced cancer patients," Palliative Medicine, vol. 18, no. 3, pp. 184-194, 2004.

[5] M. Leonard, J. Spiller, J. Keen, A. MacLullich, B. Kamholtz, and D. Meagher, "Symptoms of depression and delirium assessed serially in palliative-care inpatients," Psychosomatics, vol. 50, no. 5, pp. 506-514, 2009.

[6] J. R. Fann, C. M. Alfano, S. Roth-Roemer, W. J. Katon, and K. L. Syrjala, "Impact of delirium on cognition, distress, and healthrelated quality of life after hematopoietic stem-cell transplantation," Journal of Clinical Oncology, vol. 25, no. 10, pp. 1223-1231, 2007.

[7] T. Morita, Y. Tei, and S. Inoue, "Impaired communication capacity and agitated delirium in the final week of terminally ill cancer patients: prevalence and identification of research focus," Journal of Pain and Symptom Management, vol. 26, no. 3, pp. 827-834, 2003.

[8] M. Leonard, B. Raju, M. Conroy et al., "Reversibility of delirium in terminally ill patients and predictors of mortality," Palliative Medicine, vol. 22, no. 7, pp. 848-854, 2008.

[9] M. González, G. Martínez, J. Calderón et al., "Impact of delirium on short-term mortality in elderly inpatients: a prospective cohort study," Psychosomatics, vol. 50, no. 3, pp. 234-238, 2009.

[10] D. K. Kiely, E. R. Marcantonio, S. K. Inouye et al., "Persistent delirium predicts greater mortality," Journal of the American Geriatrics Society, vol. 57, no. 1, pp. 55-61, 2009.

[11] J. Witlox, L. S. M. Eurelings, J. F. M. De Jonghe, K. J. Kalisvaart, P. Eikelenboom, and W. A. van Gool, "Delirium in elderly patients and the risk of postdischarge mortality, institutionalization, and dementia: a meta-analysis," The Journal of the American Medical Association, vol. 304, no. 4, pp. 443-451, 2010.

[12] J. R. Basinski, C. M. Alfano, W. J. Katon, K. L. Syrjala, and J. R. Fann, "Impact of delirium on distress, health-related quality of life, and cognition 6 months and 1 year after hematopoietic cell transplant," Biology of Blood and Marrow Transplantation, vol. 16, no. 6, pp. 824-831, 2010.

[13] D. S. Davydow, "Symptoms of depression and anxiety after delirium," Psychosomatics, vol. 50, no. 4, pp. 309-316, 2009.

[14] C.-K. Fang, H.-W. Chen, S.-I. Liu, C.-J. Lin, L.-Y. Tsai, and Y.-L. Lai, "Prevalence, detection and treatment of delirium in terminal cancer inpatients: a prospective survey," Japanese Journal of Clinical Oncology, vol. 38, no. 1, pp. 56-63, 2008.

[15] T. Wada, M. Wada, M. Wada, and H. Onishi, "Characteristics, interventions, and outcomes of misdiagnosed delirium in cancer patients," Palliative and Supportive Care, vol. 8, no. 2, pp. 125-131, 2010.

[16] L. J. Beglinger, J. A. Mills, S. M. Vik et al., "The neuropsychological course of acute delirium in adult hematopoietic stem cell transplantation patients," Archives of Clinical Neuropsychology, vol. 26, no. 2, pp. 98-107, 2011.

[17] J. R. Fann, R. A. Hubbard, C. M. Alfano, S. Roth-Roemer, W. J. Katon, and K. L. Syrjala, "Pre- and post-transplantation risk factors for delirium onset and severity in patients undergoing hematopoietic stem-cell transplantation," Journal of Clinical Oncology, vol. 29, no. 7, pp. 895-901, 2011.
[18] R. Sagawa, T. Akechi, T. Okuyama, M. Uchida, and T. A. Furukawa, "Etiologies of delirium and their relationship to reversibility and motor subtype in cancer patients," Japanese Journal of Clinical Oncology, vol. 39, no. 3, pp. 175-182, 2009.

[19] J.-D. Gaudreau, P. Gagnon, F. Harel, M.-A. Roy, and A. Tremblay, "Psychoactive medications and risk of delirium in hospitalized cancer patients," Journal of Clinical Oncology, vol. 23, no. 27, pp. 6712-6718, 2005.

[20] W. Breitbart, C. Gibson, and A. Tremblay, "The delirium experience: delirium recall and delirium-related distress in hospitalized patients with cancer, their spouses/caregivers, and their nurses," Psychosomatics, vol. 43, no. 3, pp. 183-194, 2002.

[21] P. G. Lawlor, R. L. Fainsinger, and E. D. Bruera, "Delirium at the end of life: critical issues in clinical practice and research," The Journal of the American Medical Association, vol. 284, no. 19, pp. 2427-2429, 2000.

[22] E. Bruera, S. H. Bush, J. Willey et al., "Impact of Delirium and recall on the level or distress in patients with advanced cancer and their family caregivers," Cancer, vol. 115, no. 9, pp. 20042012, 2009.

[23] C. Brauer, R. S. Morrison, S. B. Silberzweig, and A. L. Siu, "The cause of delirium in patients with hip fracture," Archives of Internal Medicine, vol. 160, no. 12, pp. 1856-1860, 2000.

[24] S. K. Inouye, L. Leo-Summers, Y. Zhang, S. T. Bogardus Jr., D. L. Leslie, and J. V. Agostini, "A chart-based method for identification of delirium: validation compared with interviewer ratings using the confusion assessment method," Journal of the American Geriatrics Society, vol. 53, no. 2, pp. 312-318, 2005.

[25] "What is advanced cancer," 2012, http://www.cancer.org/.

[26] K. J. Neufeld, M. J. Hayat, J. M. Coughlin et al., "Evaluation of two intensive care delirium screening tools for non-critically ill hospitalized patients," Psychosomatics, vol. 52, no. 2, pp. 133-140, 2011.

[27] J. A. Spiller and J. C. Keen, "Hypoactive delirium: assessing the extent of the problem for inpatient specialist palliative care," Palliative Medicine, vol. 20, no. 1, pp. 17-23, 2006. 


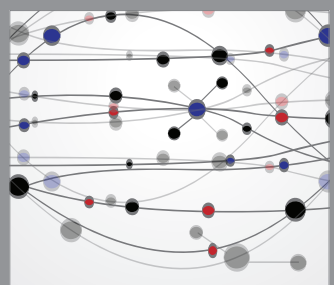

The Scientific World Journal
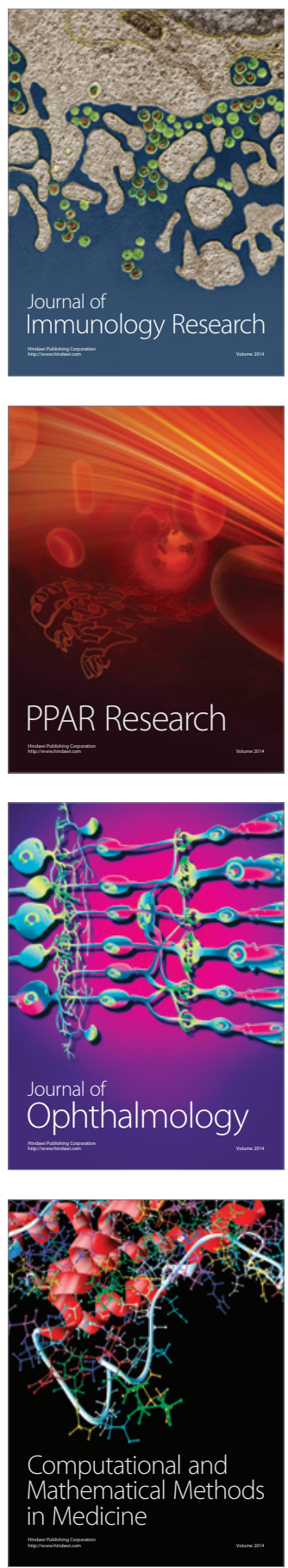

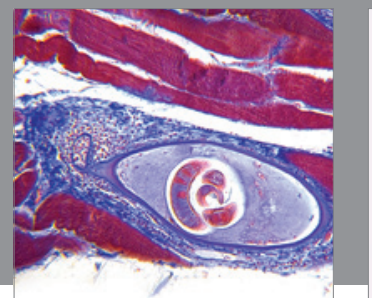

Gastroenterology

Research and Practice
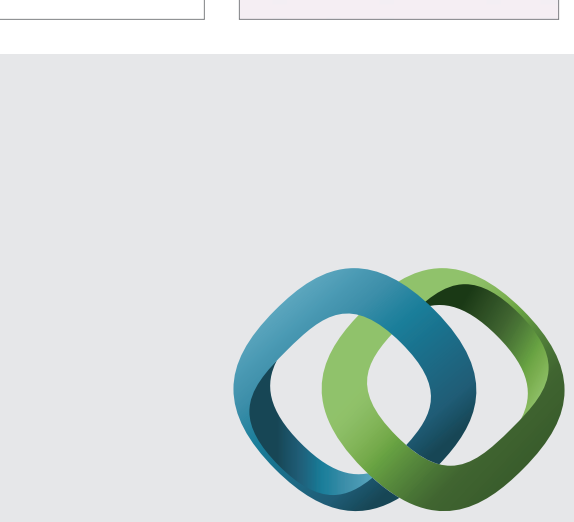

\section{Hindawi}

Submit your manuscripts at

http://www.hindawi.com
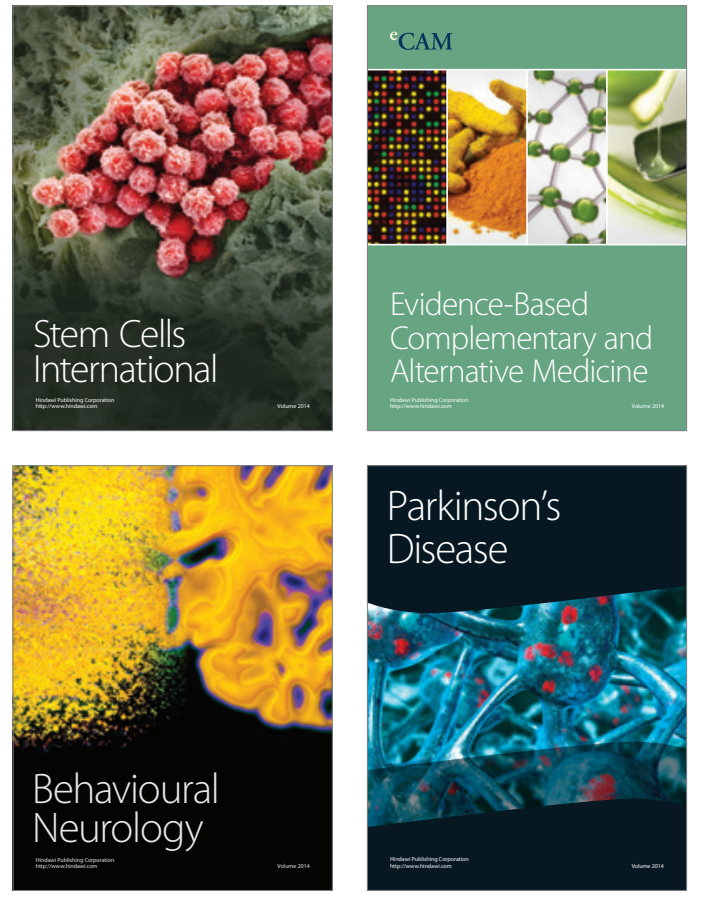
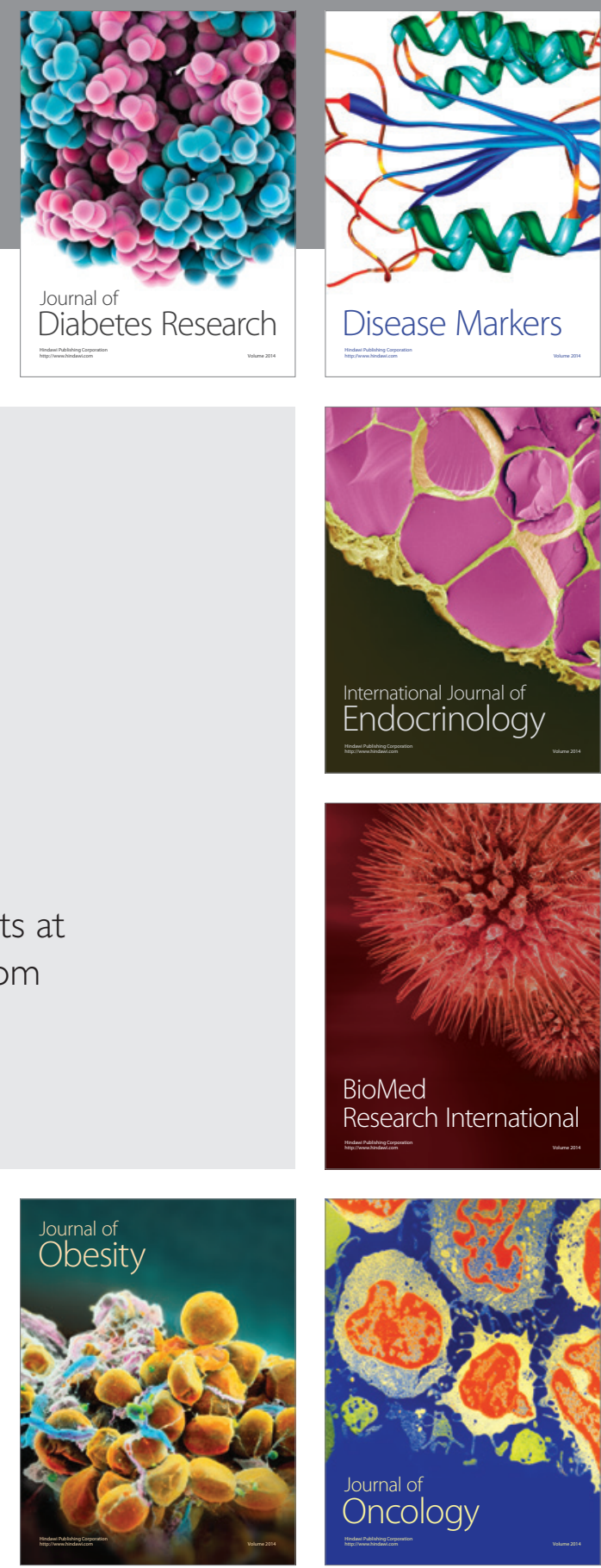

Disease Markers
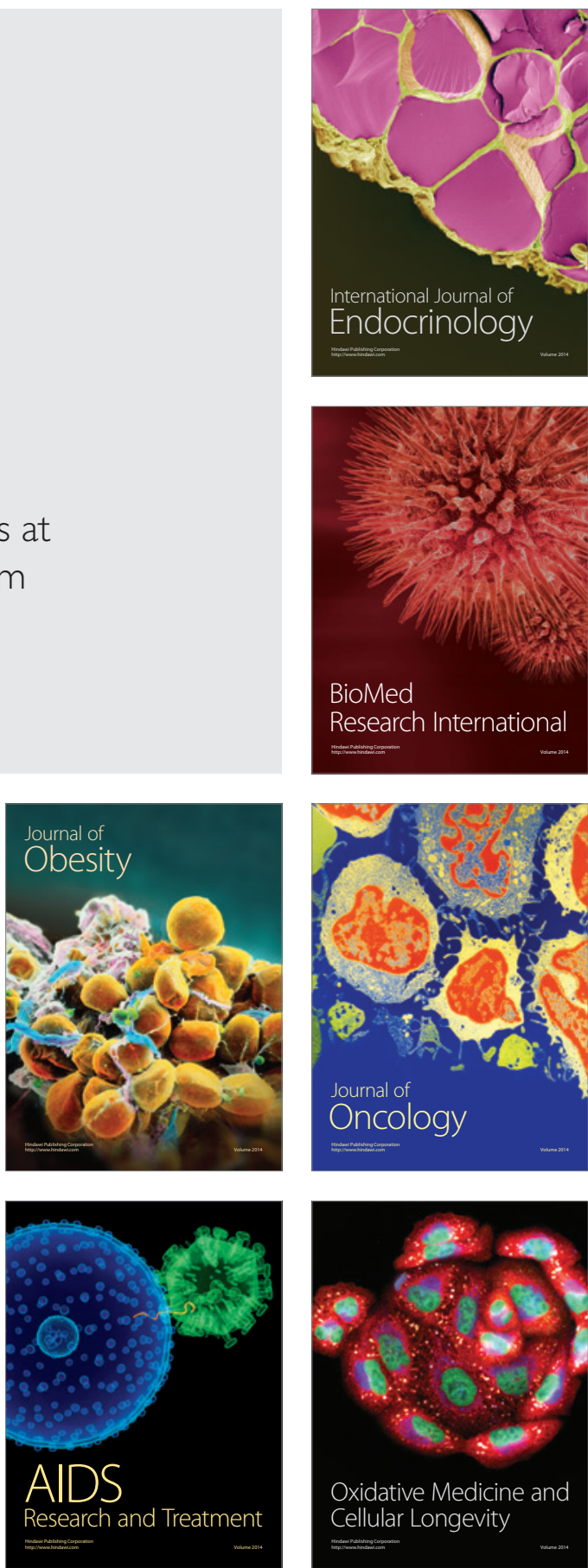